\title{
El Departamento de Documentación de los Servicios Informativos de la Cadena SER en Madrid: un poco de historia
}

\section{Placido Díez}

Radio Zaragoza - Informativos

\subsection{Resumen}

Se presenta la génesis y evolución del Departamento de Documentación de los Servicios Informativos de la Cadena SER en Madrid.

Palabras clave: Unidades de información y documentación. Historia. Cadena SER.

\subsection{Abstract}

The genesis and evolution of the documentation department of the informative services of the Spanish broadcasting company "Cadena SER" are presented.

Keywords: Information and documentation units. History. Cadena SER.

\section{Introducción}

Cuando en febrero de 1981 se desarrollan en el Congreso de los Diputados los acontecimientos del intento de golpe de estado del 23-F, la Cadena SER se encuentra, de repente, con decenas de cintas magnetofónicas, grabadas dentro del hemiciclo, durante aquella fatídica noche.

Aquellas cintas, que recogen toda la tensión del momento, las protestas de los diputados, los disparos de la Guardia Civil y el desenlace final, con la salida de los parlamentarios, se convierten en parte de la historia reciente de nuestro país.

Es entonces, cuando los responsables de emisiones se plantean una cuestión: “¿Donde guardamos estas cintas?”.

Hasta ese momento, los archivos sonoros de la Cadena han conservado la producción propia de la casa — fundamentalmente las radionovelas-, y es conocida por su riqueza documental la fonoteca de Radio Barcelona, denominada ARCHIMAG, hoy en proceso de renovación gracias a un convenio entre la Generalitat de 
Catalunya y PRISA. Algunas emisoras conservan también los documentos sonoros que creen de interés, pero no hay un sistema común de archivo.

A partir de esa fecha, 1981, se iniciará la creación de una fonoteca que conserve documentos sonoros de interés general, emitidos en la Cadena SER, y que puedan ser utilizados tras un sencillo método de búsqueda.

En 1989, aprovechando las reformas en las instalaciones de la SER, en la Gran Vía de Madrid, se crea el departamento de Documentación, que administra los fondos de la antigua fonoteca, y amplía su servicio a otras áreas de documentación escrita.

\section{El Departamento de Documentación en los medios de Comunicación}

Es evidente que los medios de comunicación están abandonando la idea de que la documentación, o "el archivo", es un lugar polvoriento donde duermen periódicos viejos, folios amarillentos o fotografías cuarteadas.

Son innegables las ventajas que ofrece al redactor tener al alcance de la mano datos, hechos pasados, cifras, que puedan darle una idea más amplia del tema que va a tocar. Ya hay pocos periodistas que desdeñen la documentación, enfrentándola a la noticia de última hora. Y no son pocos los que acuden al servicio de documentación, incluso, cuando la imaginación se seca y el tema a abordar es difícil de hincar el diente.

El servicio de documentación se revela, entonces, como caja de Pandora, de la que puede salir un dato curioso que proporciona un aspecto nuevo al asunto, una vieja noticia que ahora cobra relevancia, una biografía que da todo el sentido a la actualidad del personaje.

Si en la prensa escrita la importancia del departamento de documentación se ve tan solo con hojear cualquier día el periódico, en la radio se comprueba mucho más la oportunidad que proporciona un buen archivo sonoro. Nada más gratificante que contraponer a las declaraciones de un político, - hechas en el día de hoy—, otras realizadas hace tiempo, donde decía todo lo contrario. Nada más agradecido que un documento sonoro que nos recuerda un hecho dramático, histórico, mucho tiempo después, cuando hay que refrescar la memoria con algo más que la fecha y los datos.

Los avances técnicos e informáticos han venido, además, a reforzar esta importancia de la documentación en los medios informativos, sólo frenada por la crisis económica, que impide a las empresas periodísticas invertir en departamentos donde la rentabilidad solo se comprueba a medio y largo plazo. 


\section{Criterios para la creación del Departamento de documentación de la SER}

Por todo lo antes expuesto, los criterios que se abordaron a la hora de crear un departamento de Documentación para los Servicios Informativos de la Cadena SER fueron los siguientes:

- Debía ser riguroso y actualizado.

- Debía ser rápido y fácil de manejo.

- Y lo más importante, rentable y barato.

Las distintas experiencias documentales que se habían ensayado en los Servicios Informativos de la SER habían fallado por su falta de continuidad. Y nada más inútil que un servicio de documentación que no está al día. La gestión de la fonoteca, en la que se guardaban los documentos sonoros con un lapso de tiempo de entre 15 y 30 días resultaba excesivamente lenta para las necesidades de unos informativos que se realizan cada día y cuyas noticias, muchas veces, son consecuencia de otras anteriores.

Por ello, la primera decisión es que se trabajara en los informativos diariamente, y los documentos sonoros seleccionados se ofertaran a los redactores con un atraso máximo de 1 o 2 días, lo justo para editar, indizar y dar salida a cada uno de ellos.

Este trabajo, auténtica labor a destajo del departamento, es el más arduo del mismo, pero también el que más brilla en antena, por lo que no se ahorran esfuerzos para tener la fonoteca siempre al día, no sólo con los documentos propios, sino también con algunos de otros medios de comunicación de interés especial.

En segundo lugar, el departamento de documentación se creó con la visión realista de que no estaría compuesto por un gran número de documentalistas que gestionaran los fondos, los sirvieran a los redactores, etc. Por tanto, debía ser de fácil manejo, para usuarios no expertos, y rápido a la hora de encontrar los documentos deseados.

Estas condiciones se cumplieron a rajatabla: hoy, todos los redactores de los Servicios Informativos Centrales de la SER pueden acceder a los fondos documentales desde su propia pantalla de ordenador, y la sencillez de regrabación en cualquiera de las cabinas o estudios destinados al efecto hace que tengan su documento sonoro en pocos minutos, sin necesidad de rellenar fichas, solicitudes, etc. (Este sistema tendrá su continuación cuando se emplee el sonido digital, próximamente).

Finalmente, la condición de rentabilidad es obvia: el departamento sólo cuenta con dos personas para gestionarlo, dedicadas íntegramente a él y que además de cumplir las funciones de registro, edición, etc., llevan a antena, cuando se requiere su presencia, piezas especiales que ilustran cualquier acontecimiento.

Scire. $7: 2$ (jul.-dic. 2001) 151-156. 


\section{El funcionamiento del Departamento de Documentación}

El citado departamento de Documentación consta de:

- Fonoteca

- Biblioteca

- Hemeroteca

- Base de datos

La fonoteca está basada en la conservación de documentos sonoros emitidos por la SER tanto en sus espacios informativos como en sus programas en cadena, y siempre bajo criterios informativos.

En circunstancias especiales se conservan documentos sonoros emitidos por otros medios de comunicación, cuyo interés es especial.

El soporte de la fonoteca es la cinta abierta, a la velocidad de 7 y1/2, susceptible de ser reproducida instantáneamente en cualquiera de los estudios o cabinas de grabación de la emisora. En estos momentos se estudia la posibilidad de variar el soporte a un sistema más moderno — digitalización—, aunque la decisión estaría sujeta a que todos los estudios se adaptaran a ese mismo sistema.

En cuanto a la indización, se realiza en un programa informático diseñado especialmente para la SER, mediante un sistema de listado, fácil de manejo para personal no iniciado y al que tienen acceso todos los redactores, a través de su propia pantalla. El programa ha sacrificado potencia en aras de la sencillez para poder ser consultado sin ayuda el departamento. También en este sentido se va a exportar toda la catalogación a una base de datos, Hércules, diseñada para el diario El Pais, y que se espera que sea la base de datos de todo el Grupo Prisa en poco tiempo.

La biblioteca consta en la actualidad de unos quinientos volúmenes de consulta, entre los que destacan enciclopedias, diccionarios, textos legales y anuarios. Muchos de estos ejemplares se van reponiendo de acuerdo con su actualización, de tal forma que se dan salida a aquellos a los que viene a sustituir otro con datos más modernos. Es, por ejemplo, el caso de los anuarios estadísticos, las memorias de ministerios o instituciones públicas, etc.

La hemeroteca está compuesta por unos treinta títulos, entre ellos todos los diarios de ámbito nacional, una selección de diarios extranjeros, revistas de información general, de actualidad económica y de ciertas especialidades.

Los diarios se mantienen quice días. Los semanarios, tres meses. A continuación se hace un vaciado destinado a carpetas bajo un índice temático que también se indiza en el programa informático antes citado.

La base de datos que maneja la redacción de Informativos de la SER es la del diario EL PAIS, a la que accedemos mediante red. Es una base de datos comple- 
ta, que incluye todos y cada uno de los artículos del periódico desde 1976, tanto en texto como en formato periódico, una vez escaneados. Esta base constituye una importante ayuda para la labor diaria de los redactores, si bien se procura en todo momento completar esa documentación con la procedente de otros medios escritos. Otras bases de datos a las que estamos suscritas son EFEDATA, de la Agencia EFE, la edición digital del BOE, etc.

\section{4. ¿Por qué crear un Departamento de Documentación?}

Cuando en 1981 se produjo el intento de golpe de Estado del 23-F, la SER se encontró con un problema: ¿Dónde guardar las cintas en las que se había grabado todo el episodio del Congreso de los Diputados?

Fue entonces cuando se consideró por primera vez la necesidad de un departamento de Documentación, pero se pensó que para guardar las cintas interesantes sólo se necesitaba un técnico que ocupara un par de horas de su jornada laboral. El intento fructificó gracias a la tenacidad de aquel técnico, pero fracasó en cuanto éste se jubiló, dos años después.

De aquella etapa quedaron en Radio Madrid 1.200 cintas, con un precario sistema de indización, ya que nadie le asesoró sobre sistemas lógicos de documentación. Esto ha supuesto luego que sí existan documentos sonoros, pero que sea muy difícil saber qué hay en cada uno, porque la catalogación de temas es muy rudimentaria.

Años después, en 1989, Angeles Afuera, la actual responsable del departamento, sugirió al entonces director de los Informativos, José María Baviano, la creación de un servicio de Documentación, aquel que tantas veces nos hubiera hecho falta años atrás y que nunca fructificó. Se partió de cero y después de conocer otros departamentos de medios de comunicación — RTL, Radio Barcelona, TV-3 y, aquí, en Madrid, Radio Nacional, TVE y EL PAIS - se emprendió la tarea.

La dirección general y la dirección de Informativos colaboraron con interés en su puesta en marcha, y se produjo una inversión inicial para la compra de la biblioteca de consulta, una lectora de microfichas, y una cabina de reproducción. En la actualidad, el Departamento de Documentación de la SER cuenta con un fondo de documentación escrita - la colección microfilmada de EL PAIS y su base de datos-; una hemeroteca en continua renovación; una biblioteca viva de consulta; y una fonoteca clasificada mediante un programa informático diseñado por nosotros mismos. El Departamento está atendido exclusivamente por Angeles Afuera, que considera que en ocasiones sería muy conveniente tener más personas trabajando en él, porque no sólo suministra documentación a los Servicios Informativos, sino a la redacción de Programas y a las emisoras que solicitan algún servicio. En los últimos tiempos, y cuando ya el departamento se

Scire. $7: 2$ (jul.-dic. 2001) 151-156. 


\section{Placido Díez}

ha consolidado, a las tareas habituales se ha unido la entrada en antena de Angeles Afuera con piezas de documentación que puedan enriquecer el tema del que se trata. De esta manera se ha cerrado un ciclo y se está dando una personalidad a los informativos que otras cadenas de radio no tienen.

\section{Conclusión}

El Departamento de Documentación es un servicio indispensable en cualquier medio de comunicación, puesto que la información no se basa sólo en noticias, sino en todo lo que pueda acompañarlas. La puesta en antena de un producto completo, —noticia, documentación, entrevista adecuada, etc.— mejora indiscutiblemente la mera relación de hechos que han sucedido durante el día. 